\title{
Applying Concept Map to Game-Base Concept Assessment
}

https://doi.org/10.3991/ijim.v14i06.12057

\author{
Chien-Hung Lai ${ }^{(凶)}$, Bin-Shyan Jong, Yen-Teh Hsia \\ Chung Yuan Christian University, Taoyuan, Taiwan \\ soulwindecycu.org.tw \\ Tsong-Wuu Lin \\ Soochow University, Taipei, Taiwan
}

\begin{abstract}
There have been lots of studies using traditional concept assessment to measure student's learning achievement. This study adding game elements in concept assessment try to measure student's learning achievement, and compare this result with traditional concept assessment to see what's the difference between traditional concept assessment and adding game element in concept assessment. Traditional concept assessment using SPRT method in multiple-choice to measure student's concept mastery, our study using the same method and present this method in concept game so that student won't feel boring and tiring during this assessment. Our study observe each student's feedback and their concept mastery by using game element to display concept assessment, and analyze is using concept game assessment can shorten student's test time and improve student learning concept knowledge after assessment, the result shows that when student using concept game assessment they can know their concept mastery immediately by seeing process bar present as their life so the test time will be shorten, and student's concept knowledge was improved after concept game assessment. Student's feedback shows that they prefer concept game assessment because they can measure their concept mastery during the concept game assessment; this study shows that adding game element in concept assessment can improve student's concept mastery and shorten the test time student took.
\end{abstract}

Keywords—Concept assessment, concept game assessment, SPRT, concept mastery.

\section{Introduction}

Traditional teaching mainly uses tests to understand students' learning condition. Therefore, when there are too many test questions or too many tests, students will be fed up with tests and their learning motivation will decrease. If some interesting elements are added to tests, students' learning condition can be measured and they may become more interested in courses and more diligent in learning. 
Many studies have verified that game-based learning can increase students' learning motivation [1] [2] [8]. The addition of game situations to teaching materials enables students to learn in fun ways and further increase their learning motivation. Moreover, test results can be used to understand the effectiveness of students' use of game-based learning. Compared with the teaching tests in traditional teaching where tests are used to test students' learning progress and students certainly will prepare for them in advance, game-based teaching uses the same approach to test students' learning progress. However, this study intends to investigate whether it is possible to test students in a more relaxed manner without informing them of tests in advance and whether students can reflect their learning effectiveness of the concepts of chapters during the tests.

Traditional tests still are required to be used to test learning effectiveness in some of the game-based learning. Therefore, this study proposed the test of game-based concept map to enable students to maintain their motivation to use the test during the test of course concept without experiencing learning fatigue due to high frequency of tests. This study designed a game-based concept map test system to enable students to reflect their learning in a game-based manner during the use of concept test, as well as to enable them to fully reflect their learning condition after operation. Moreover, this study also compared the game-based concept map test with general traditional concept map test.

\section{Literature Review}

\subsection{Game-based learning}

Due to the gradual development of computer games, it has become a trend to add teaching materials to computer games to enable students to further develop learning interest through their interest in games. Moreover, compared with general traditional learning, game-based learning can maintain students' learning motivation because it enables students to actively participate in game activities. Therefore, a well-designed game can assist students in learning.

According to relevant studies, the characteristics of game-based learning environment are as follows [6]:

- Integrating course content into games to enable students to understand the knowledge and content of courses through the games. Compared with the learning methods of traditional courses, it brings different experiences to learners.

- Learners can solve the difficult problems they encounter through the knowledge obtained from games, as well as verify whether they can understand or are familiar with the course content.

- The instant feedback provided by games enables learners to understand whether the knowledge they obtain is accurate according to the feedback, as well as constantly revise their answers through the feedback, to further complete their learning. 
The provision of tests or levels of different difficulty levels enables students to perform the self-test, as well as to understand their level of understanding of course knowledge

\subsection{Computer-based testing}

Nowadays, with the rapid development of computer-based teaching, some scholars have investigated the effect of used of computer in teaching tests [10]. The use of computer in the tests of various fields has become the approach that many scholars intend to investigate because the use of computer in tests can rapidly obtain the information on user status.

Some scholars have also discovered that the use of computer not only reduces the time of tests, but also increases users' participation motivation [9]. To education and teaching courses, the use of computer in tests has become a catalyst catalyzing the transformation of learning types.

It is uncertain whether the effectiveness of the use of computer in tests is the same as that of the use of written tests. Some people question the effectiveness in certain courses, such as mathematics, science \& technology, language. Some scholars used biology course to test whether the effectiveness of computer-based test is the same as that of written test. A study found that the effectiveness of computer-based test is the same as that of written test [10]. Therefore, the use of computer in tests has become a gradually practical approach.

\subsection{Concept map test}

In addition to the general written tests, other studies have proposed different measurement methods, such as oral report and specific project, as the tests for students' learning condition. Although oral reports and specific project enable students to develop their own knowledge framework without being restricted by regulations [5], the knowledge framework reflected by students according to the measurement results are completely different. Therefore, it is impossible to understand students' exact learning condition.

Concept map test has been verified as an effective tool which can assist students in expressing the knowledge they have learned [3][4]. The use of structural characteristics of concept map enables students to understand their own knowledge level, and enables teachers to implement remedial teaching according to students' familiarity of concept map. For example, concept map system can be used to assist students in English writing training [7], or the knowledge building methods of concept map can be used to help students improve their ability to tell a story or an event [7].

The concept map included two parts. Part 1 was concept mapping. This part was teachers' and experts' analysis on the concepts covered in courses and the connection among concepts, as well as the development of corresponding figure of course concepts. Part 2 was the concept map evaluation. This part was to have students take the tests of various concepts, and teachers could understand students' familiarity with 
each concept based on their test results. Moreover, they could adjust the courses according to students' learning condition of course concepts [5].

\section{Game-Base in Concept Assessment System Design}

A scholar has used role-playing to enable students to integrate themselves to teaching game situations in the past study on game-based learning, in order to increase students' interest in concepts and learning motivation [1]. Therefore, based on the past study, this study added game elements to tests to analyze whether game-based concept map test can more effectively understand students' familiarity with concepts than traditional concept map system can, and investigated the influence of game-based concept map test and traditional concept map test on students, in order to find out the test method applicable to students.

Firstly, students would log in their accounts through a start page, and their registration information could be used for testing. The users would be introduced to the game page to take the concept test game if their accounts and passwords match. The users would be introduced to the results page when the game of concept of a stage is ended. The users could see whether they succeeded or failed in the learning of concept.

A. Animation Display Area: The display of ongoing games and animations. This study used the game of castle guardian. When students answered questions, the soldiers of the two parties would attack one another.

B. Q\&A Interactive Area: When users clicked the attack button, questions would be generated for them to answer. In addition, animation would be displayed in the central display area to enable them to understand whether their answer was wrong or right.

C. Concept Progress Bar: The progress bar would be generated according to the values input in the SPRT formula when students' answers were right or wrong to enable them to understand their current progress (the red denotes the current progress. When the bar is fully in red, the students succeed in the learning of the concept. When the bar is not in red, the students fail in the concept).

D. Text Message Area: The name of the current concept is displayed here. When students answered the questions, the corresponding text messages would be displayed according to the students' answers.

E. Game Message Area: This area instructed students whether to attack or not. Moreover, the messages of success and failure would be displayed when students succeeded or failed in the learning of concept.

The results page was divided into three major blocks:

a. The success or failure of learning of each concept was displayed through text messages to enable users to understand whether they succeeded or failed in answering the question of concept.

b. Results block: the proportion of number of right and wrong answers of users was displayed. A bar chart was drawn according to the proportion. 
c. Score block: the score of students was displayed. The score of students was calculated according to the number of right and wrong answers to the questions of concept. The students could refer to their total score of the learning of the current concept according to this score since the score was calculated using the proportion.

After entering the system, the students clicked "Attack." The animation of soldiers of the two parties attacking one another would be displayed on the screen. Once the soldiers attacked one another, the system would randomly select a question of a concept. The soldiers above the screen would keep attacking one another. After the users clicked "Submit," the display area would determine the soldiers of which party won according to the answer (right or wrong) and enable the winning soldiers to move towards the castle of the losing ones. When the value obtained from the SPRT formula reached specific proportion, the castle would be damaged to a different extent.

The success and failure in the learning of a concept was subject to the damage of the castle. Because the SPRT calculation cannot determine the result of the learning of concept under the situation of repeated right and wrong answers, the concept "partial familiarity" was added in the experiment.

\section{Experimental Procedure}

The research subjects were the students taking the course of operating system. A total of 139 subjects were selected, and they were divided into two classes, class A and class B. This experiment tested 5 concepts concerning the operating system, including brief introduction to operating system, computer system structure, operating system, processing elements and central processor scheduling. Class A was firstly tested using the traditional concept map test system, and then was tested using the game-based concept map test system. Class B was firstly tested using the game-based concept map test system, and then was tested using the traditional concept map test system. The experiment mainly investigated the effect of game-based concept test system on concept testing. The experiment compared the test results of the students using the two systems as the validity of the system concept test. According to the experiment results, 96 students completed the experiment, including 43 students in class A and 53 students in class B.

The experimental procedures were: students used two systems, respectively. Multiple choice questions were used in the system for testing. In the experiment, the same question back was used in the experiment for the concept test. During the test, the students used two systems one by one. Because students would engage in impressionbased learning of concepts after using the systems, they would pass the test using learning memory if there were similar questions. Therefore, this study adjusted the experiment data according to the post-learning. TABLE I is the set-up of pre-and-post concept maps. If the previous concept test was a success $(\mathrm{S})$ and the next one was a failure $(\mathrm{F})$ or partial learning $(\mathrm{P})$, the students' performance would be regarded as regress and two different values $(2,0)(2,1)$ would be offered.

The reason why the result of former concept as partial learning $(\mathrm{P})$ and the next one as a failure $(\mathrm{F})$ was that, partial learning represented that students did not fully under- 
stand the knowledge of the concept. In other words, the system was not sure whether the students understood the content of the concept. As a result, the value $(\mathrm{P})$ offered to the students represented partial learning. Failure represented that students were not familiar with the content of the concept. Therefore, when the students' former concept was partial learning and the next one was a "failure," this study offered them the value $(1,1)$ for comparison. If the pre-test of the concept was a failure $(F)$ and the post-test of it was partial learning $(\mathrm{P})$ and the students improved their test result of the concept from failure to partial learning due to the test learning, this study would also offer them the value $(0,0)$ for comparison.

Table I. The consistency of the concept results set

\begin{tabular}{|c|c|l|}
\hline First do concept & After do concept & \multicolumn{1}{|c|}{ Condition and encode } \\
\hline S & F & Regress (2,0) \\
\hline S & P & Regress (2, 1) \\
\hline F & S & Progress (2, 2) \\
\hline P & S & Progress (2, 2) \\
\hline F & P & Fair $(0,0)$ \\
\hline$S$ & S & Fair $(1,1)$ \\
\hline F & F & Fair $(0,0)$ \\
\hline$P$ & P & Fair $(1,1)$ \\
\hline$P$ & F & Fair $(1,1)$ \\
\hline
\end{tabular}

\section{Result and Discussion}

TABLE II to TABLE VII are the Pearson's test on concept $1 \sim 5$ and the overall concept. The results showed that, there was a significant correlation between the two systems, suggesting that the two systems were correlated. Moreover, there was a high correlation between them, which further showed that the effectiveness of the two systems was the same. 
Table 1. Concept 1 Pearson Correlation

\begin{tabular}{|l|l|c|c|}
\hline \multicolumn{2}{|l|}{ Concept 1 } & First Game & First Concept \\
\hline \multirow{4}{*}{ First Game } & Pearson Correlation & 1 & $.816^{* *}$ \\
\cline { 2 - 4 } & Sig. (two-tailed) & & .000 \\
\cline { 2 - 4 } & $\mathrm{N}$ & 97 & 97 \\
\hline \multirow{3}{*}{ First Concept } & Pearson Correlation & $.816^{* *}$ & 1 \\
\cline { 2 - 4 } & Sig. (two-tailed) & .000 & 97 \\
\cline { 2 - 4 } & $\mathrm{N}$ & 97 & 97 \\
\hline
\end{tabular}

Table 2. Concept 2 Pearson Correlation

\begin{tabular}{|l|l|c|c|}
\hline \multicolumn{2}{|l|}{ Concept 2 } & First Game & First Concept \\
\hline First Game & Pearson Correlation & 1 & $.812^{* *}$ \\
\cline { 2 - 4 } & Sig. (two-tailed) & & .000 \\
\cline { 2 - 4 } & $\mathrm{N}$ & 97 & 97 \\
\hline First Concept & Pearson Correlation & $.812^{* *}$ & 1 \\
\cline { 2 - 4 } & Sig. (two-tailed) & .000 & 97 \\
\cline { 2 - 4 } & $\mathrm{N}$ & 97 & 97 \\
\hline
\end{tabular}

Table 3. Concept 3 Pearson Correlation

\begin{tabular}{|l|l|c|c|}
\hline \multicolumn{2}{|l|}{ Concept 3 } & First Game & First Concept \\
\hline \multirow{5}{*}{ First Game } & Pearson Correlation & 1 & $.827^{* *}$ \\
\cline { 2 - 4 } & Sig. (two-tailed) & & .000 \\
\cline { 2 - 4 } & $\mathrm{N}$ & 97 & 97 \\
\hline \multirow{3}{*}{ First Concept } & Pearson Correlation & $.827^{* *}$ & 1 \\
\cline { 2 - 4 } & Sig. (two-tailed) & .000 & 97 \\
\cline { 2 - 4 } & $\mathrm{N}$ & 97 & 97 \\
\hline
\end{tabular}

Table 4. Concept 4 Pearson Correlation

\begin{tabular}{|l|l|c|c|}
\hline \multicolumn{2}{|l|}{ Concept 4 } & First Game & First Concept \\
\hline \multirow{4}{*}{ First Game } & Pearson Correlation & 1 & $.903^{* *}$ \\
\cline { 2 - 4 } & Sig. (two-tailed) & & .000 \\
\cline { 2 - 4 } & $\mathrm{N}$ & 97 & 97 \\
\hline \multirow{3}{*}{ First Concept } & Pearson Correlation & $.903^{* *}$ & 1 \\
\cline { 2 - 4 } & Sig. (two-tailed) & .000 & 97 \\
\cline { 2 - 4 } & $\mathrm{N}$ & 97 & \\
\hline
\end{tabular}

Table 5. Concept 5 Pearson Correlation

\begin{tabular}{|l|l|c|c|}
\hline \multicolumn{2}{|c|}{ Concept 5 } & First Game & First Concept \\
\hline \multirow{4}{*}{ First Game } & Pearson Correlation & 1 & $.882^{* *}$ \\
\cline { 2 - 4 } & Sig. (two-tailed) & & .000 \\
\cline { 2 - 4 } & $\mathrm{N}$ & 97 & 97 \\
\hline \multirow{3}{*}{ First Concept } & Pearson Correlation & $.882^{* *}$ & 1 \\
\cline { 2 - 4 } & Sig. (two-tailed) & .000 & 97 \\
\cline { 2 - 4 } & $\mathrm{N}$ & 97 & 97 \\
\hline
\end{tabular}


Table 6. Concept 1 to Concept 5 Pearson Correlation

\begin{tabular}{|l|l|c|c|}
\hline \multicolumn{2}{|c|}{ Concept 1 to Concept 5 } & First Game & First Concept \\
\hline \multirow{4}{*}{ First Game } & Pearson Correlation & 1 & $.856^{* *}$ \\
\cline { 2 - 4 } & Sig. (two-tailed) & & .000 \\
\cline { 2 - 4 } & $\mathrm{N}$ & 485 & 485 \\
\hline \multirow{3}{*}{ First Concept } & Pearson Correlation & $.856^{* *}$ & 1 \\
\cline { 2 - 4 } & Sig. (two-tailed) & .000 & 485 \\
\cline { 2 - 4 } & $\mathrm{N}$ & 485 & \\
\hline
\end{tabular}

The experiment found that, because the students used the traditional concept map test and game-based concept map test to take their tests of concepts, they might learned from the former test system, which led to the fact that the students could learn the concepts through system and complete the answers when the questions of concepts were displayed. Therefore, this study classified the data, and performed the analysis on the correlation among data. There was a high correlation among data, suggesting that the effectiveness of the two systems was the same.

There was a significant correlation between the two systems. This study added game elements to the tests of concepts. During the use of systems, students did not suggest that they were taking the tests of concepts. The students would learn concepts based on the questions of the tests when answering to the questions. Because this study enabled the students to use two systems one by one, the effectiveness of the test of concepts of students was better if they used game-based concept test first and then use traditional concept test.

TABLE VIII to TABLE IX are the ratios of progress and regress of class A and class B. Class A firstly used the traditional concept map to take the test, and then used game-based concept map to take the test. According to TABLE VIII, this study found that students' understanding of game-based concept map test was slightly improved after using the traditional concept map system. However, the progress was not significant. Therefore, the traditional concept map test system only had the effect of testing the learning effectiveness of concepts and could not improve students' familiarity with concepts.

On the contrary, class B used the game-based concept map test first, and then used the traditional concept map test. The results showed that, the learning of concepts was improved in the data of traditional concept map test after the students used the gamebased concept map to take the test of their learning. Therefore, after using the gamebased concept map test system, students learned the knowledge of concept through the game process and further improved their familiarity with concepts to "progress."

TABLE $X$ is the ratios of progress and regress of students' overall concept. The progress ratio of the overall familiarity with concept 1 was $6.2 \%$, while the regress ratio of learning was $6.1 \%$. The reason why the progress ratio was slightly larger than the regress ratio was that students could learn concepts through game-based map test. The overall familiarity of concept 2 improved by $11.34 \%$. This study found that after using the two systems to take tests, the students' score of the system used later (traditional concept map test) improved due to the learning of concepts. The overall progress ratio was $10.51 \%$, and the regress ratio was $8.57 \%$, suggesting that game-based 
concept map test enabled students to better understand the learning of concepts. This study regarded progress as students' progress due to the learning of concept, and regarded regress as the situation caused by the students' condition or environmental factors. Therefore, the use of systems, first or later, would lead to students' learning of concept.

Table 7. A Progress and Regress

\begin{tabular}{|l|c|c|}
\hline & Progress \% & Regress \% \\
\hline Concept 1 & $0 \%$ & $11.6 \%$ \\
\hline Concept 2 & $4.6 \%$ & $16.27 \%$ \\
\hline Concept 3 & $16.27 \%$ & $11.62 \%$ \\
\hline Concept 4 & $2.3 \%$ & $9.3 \%$ \\
\hline Concept 5 & $7 \%$ & $6.97 \%$ \\
\hline Total & $6 \%$ & $11.16 \%$ \\
\hline
\end{tabular}

Table 8. Class B Progress and Regress

\begin{tabular}{|l|c|c|}
\hline & Progress \% & Regress \% \\
\hline Concept 1 & $11.32 \%$ & $1.88 \%$ \\
\hline Concept 2 & $15.09 \%$ & $5.66 \%$ \\
\hline Concept 3 & $11.32 \%$ & $20.75 \%$ \\
\hline Concept 4 & $15.09 \%$ & $3.77 \%$ \\
\hline Concept 5 & $13.20 \%$ & $1.88 \%$ \\
\hline Total & $13.20 \%$ & $6.79 \%$ \\
\hline
\end{tabular}

Table 9. Total Progress and Regress

\begin{tabular}{|l|c|c|}
\hline & Progress \% & Regress \% \\
\hline Concept 1 & $6.18 \%$ & $6.12 \%$ \\
\hline Concept 2 & $11.34 \%$ & $10.2 \%$ \\
\hline Concept 3 & $14.43 \%$ & $16.33 \%$ \\
\hline Concept 4 & $10.30 \%$ & $6.12 \%$ \\
\hline Concept 5 & $10.30 \%$ & $4.08 \%$ \\
\hline Total & $10.51 \%$ & $8.57 \%$ \\
\hline
\end{tabular}

Compared with the traditional concept map test, the game-based concept map test displayed the success or failure of learning of concepts and progress of learning in a graphical manner. Therefore, students could better understand the changes in values and whether they were going to learn the concepts. The tests of concepts could hence be speeded up. However, on the other hand, because SRPT formula calculates familiarity according to the number of right and wrong answers, the progress ratio of students would significantly decrease when they carelessly completed the wrong answers. The students were confused with this phenomenon. Because traditional concept map test displayed values and students were less sensitive to values than to images, students would experience emotional changes according to the increase or decrease in the progress bar, which further affected their speed of tests. 
The results of the questionnaire showed that the mean of the two questionnaires was close and homogeneous (TABLE XI). However, there was no significant correlation between them. The students' motivation to use the two systems was the same.

Table II. the mean of the two questionnaires

\begin{tabular}{|c|c|c|c|}
\hline No. & Subject & Traditional & Game \\
\hline 1 & $\begin{array}{l}\text { Using the traditional concept map test (game-based concept map test) let me } \\
\text { know more about the course content. }\end{array}$ & 4.81 & 4.86 \\
\hline 2 & $\begin{array}{l}\text { After using the traditional concept map test (game-based concept map test), } \\
\text { you will understand the concept content that you are not enough. }\end{array}$ & 4.96 & 5.00 \\
\hline 3 & $\begin{array}{l}\text { I feel very happy using the traditional concept map test (game-based concept } \\
\text { map test). }\end{array}$ & 4.43 & 4.47 \\
\hline 4 & $\begin{array}{l}\text { The subject description is very complete in the traditional concept map test } \\
\text { (game-based concept map test). }\end{array}$ & 4.38 & 4.72 \\
\hline 5 & $\begin{array}{l}\text { Through the traditional concept map test (game-based concept map test), I } \\
\text { feel that the course will not be too boring. }\end{array}$ & 4.58 & 4.76 \\
\hline 6 & $\begin{array}{l}\text { I am satisfied with the graphical interface in the traditional concept map test } \\
\text { (game-based concept map test). }\end{array}$ & 4.4 & 4.35 \\
\hline 7 & $\begin{array}{l}\text { I am satisfied with the interactive way of the traditional concept map test } \\
\text { (game-based concept map test). }\end{array}$ & 4.54 & 4.39 \\
\hline 8 & $\begin{array}{l}\text { Traditional concept map test (game-based concept map test) makes me feel } \\
\text { easy to use. }\end{array}$ & 4.78 & 4.68 \\
\hline 9 & $\begin{array}{l}\text { I will promote the traditional concept map test (game-based concept map test) } \\
\text { to other students. }\end{array}$ & 4.5 & 4.54 \\
\hline 10 & I like the traditional concept map test (game-based concept map test). & 4.56 & 4.5 \\
\hline 11 & $\begin{array}{l}\text { Using traditional concept map test (game-based concept map test) makes me } \\
\text { curious about the course content. }\end{array}$ & 4.45 & 4.66 \\
\hline 12 & $\begin{array}{l}\text { Using traditional concept map test (game-based concept map test) I feel very } \\
\text { helpful to me. }\end{array}$ & 4.68 & 4.72 \\
\hline 13 & $\begin{array}{l}\text { Compared to the general paper test, I prefer to use the traditional concept map } \\
\text { test (game-based concept map test) to measure. }\end{array}$ & 4.81 & 4.62 \\
\hline 14 & $\begin{array}{l}\text { I won't be bored with traditional concept map test (game-based concept map } \\
\text { test) }\end{array}$ & 4.78 & 4.63 \\
\hline 15 & $\begin{array}{l}\text { I will strengthen my study when I use the traditional concept map test (game- } \\
\text { based concept map test) to learn the concept familiarity. }\end{array}$ & 4.88 & 4.93 \\
\hline 16 & $\begin{array}{l}\text { Using the traditional concept map test (game-based concept map test), I feel } \\
\text { that my heart beats very quickly. }\end{array}$ & 3.87 & 4.02 \\
\hline 17 & $\begin{array}{l}\text { I am annoyed when using traditional concept map test (game-based concept } \\
\text { map test). }\end{array}$ & 4.13 & 4.13 \\
\hline
\end{tabular}

During the interviews, some students mentioned that the speed of animation display would affect their motivation to use the system. For example, some students suggested that the animation display was too slow, and it took a lot of time to wait for soldiers to walk to the castle or attack one another in the middle. They could know the results of the traditional concept map test right after they completed the answers. However, some students suggested that the animation was interesting, and they liked this type of test methods. They could succeed in the learning of concepts by damaging the rival's castle. Compare with general traditional concept map test system, students preferred using game-based concept map test system. The feedback from the questionnaire showed that, more than half of the students liked game-based concept map 
test, 1/3 of them suggested that the traditional concept test was better and other 17 students did not have any opinion. Moreover, some students mentioned that the images can be simplified. The system page with too many images made it hard to read the questions.

\section{Conclusion}

The main purposes of this study are to use game-based approach to test concepts, to investigate whether the addition of game elements to tests of concepts can speed up the effect of tests and to improve students' familiarity with concepts after the tests. According to the experiment results, after using game-based concept map test system, students' familiarity with concepts was improved. Moreover, the instant display of students' current progress of learning of concepts enabled them to understand their familiarity with concepts in a timely manner. Therefore, students would not lose patience or motivation due to excessive number of questions during the test or the excessively frequent tests. According to the research findings, after using game-based concept map test, students' familiarity with concepts was improved. Therefore, if uncertain factors are added to the system and images are updated, students' motivation to use the system may be better maintained and their familiarity with concepts may be improved. For example, if students can use different functions after giving a certain number of right answers, their interest in the system will be increased and they will be more absorbed in games. Eventually, students' learning motivation will be further increased according to the results of the game-based concept map test. Compared to the general traditional concept map test, students' learning enthusiasm will be higher.

Moreover, if the effectiveness of learning of concepts can be reflected in scores, students can also better grasp their own familiarity with concepts. The experiment found that students' response to scores was stronger. If such type of test can be used to enable students to understand their level of understanding according to the tests, there is no need to perform more tests on students' learning progress of courses. It is believed that education can have more diversified effects.

\section{References}

[1]Meluso A., Zheng M., Spires H.A., \& Lester J. (2012). Enhancing 5th graders' science content knowledge and self-efficacy through game-based learning, Computers \& Education, 59(2), 497-504. https://doi.org/10.1016/j.compedu.2011.12.019

[2] Shafie A., \& Ahmad W. F. W. (2010). Design and Heuristic Evaluation of MathQuest: A Role-Playing Game for Numbers, Procedia Social and Behavioral Sciences, 8, 620625. https://doi.org/10.1016/j.sbspro.2010.12.086

[3] Chiou C. C. (2008). The effect of concept mapping on students' learning achievements and interests, Innovations in Education and Teaching International, 45(4), 375-387. https ://doi.org/10.1080/14703290802377240 
[4]Hwang G. J., Shi Y. R., \& Chu H.C. (2011). A concept map approach to developing collaborative Mindtools for context-aware ubiquitous learning, British Journal of Educational Technology, 42(5), 778-789. https://doi.org/10.1111/j.1467-8535.2010.01102.x

[5]McClure J. R., Sonak B., \& Suen H. K. (1999). Concept Map Assessment of Classroom Learning : Reliability, Validity, and Logistical Practicality, Journal of Research in Science Teaching, 36(4), 475-492. https://doi.org/10.1002/(sici)1098-2736(199904)36:4< 475::aid-tea5>3.0.co;2-o

[6] Papastergiou M. (2009). Digital Game-Based Learning in high school Computer Science education: Impact on educational effectiveness and student motivation, Computers \& Education, 52(1), 1-12. https://doi.org/10.1016/j.compedu.2008.06.004

[7]Liu P. L. (2011). A study on the use of computerized concept mapping to assist ESL learners' writing, Computers \& Education, 57(4), 2548-2558. https://doi.org/10.1016/j. compedu.2011.03.015

[8] Watson W. R., Mong C. J., \& Harris C.A. (2011). A case study of the in-class use of a video game for teaching high school history, Computers \& Education, 56(2), 466-474. https://doi.org/10.1016/j.compedu.2010.09.007

[9] Chua Y. P. (2012). Effects of computer-based testing on test performance and testing motivation, Computers in Human Behavior, 28(5), 1580-1586. https://doi.org/10.1016/ j.chb.2012.03.020

[10] Chua Y. P., \& Don Z. M. (2013). Effects of computer-based educational achievement test on test performance and test takers'motivation, Computers in Human Behavior, 29(5), 1889-1895. https://doi.org/10.1016/j.chb.2013.03.008

\section{Authors}

Chien-Hung Lai is an assistant professor in the Department of Electronic Engineering, Chung Yuan Christian University. His research interests include computer aided education.

Bin-Shyan Jong is a professor in the Department of Information and Computer Engineering, Chung Yuan Christian University. His research interests include computer graphics and computer aided education.

Yeh-Teh Hsia is now a professor in the Department of Information and Computer Engineering, Chung Yuan Christian University. His research interests include computer aided education and artificial intelligence.

Tsong-Wuu Lin is a professor in the Department of Computer Science and Information Management, Soochow University. His research interests include computer graphics and computer aided education.

Article submitted 2019-10-27. Resubmitted 2019-12-08. Final acceptance 2019-12-10. Final version published as submitted by the authors. 